\title{
Availability of Drugs for the Treatment of Parkinson's Disease, Pharmacy Network in the Municipality Riobamba
}

\author{
Guillermo GJ, Urbano SC*, Angélica BM and Silvia Johana CB \\ National University of Chimborazo, Escuela Superior Politécnica de Chimborazo
}

Received: April 16, 2018; Accepted: April 30, 2018; Published: May 14, 2018

*Corresponding author: Urbano Solis Cartas, Specialist of 1st Degree in Rheumatology and General Medicine, Researcher, Master in Satisfactory Longevity. Researcher UNACH, National University of Chimborazo. Riobamba. Chimborazo. Ecuador. Tel: 0969467803; E-mail: umsmwork74@gmail. com

\begin{abstract}
Background: Parkinson's disease is a chronic, degenerative disorder of the dopamine-producing cells, a predominantly midbrain level, the processes involved in engine control system. Its deficit is manifested by a progressive loss of the ability to coordinate movements.
\end{abstract}

Objectives: to determine the availability of drugs to control the disease in pharmacies Riobamba municipality.

Material and Methods: A descriptive study by conducting surveys in 20 pharmacies, 78 patients and 2 basic hospitals. In addition, also they surveyed six health professionals.

Results: the $90 \%$ of the extra hospital pharmacies have antiparkinsonians availability of drugs, but only $5 \%$ have biperideno and levodopa. $50 \%$ of hospital pharmacies does not guarantee a continuous supply of these drugs.

Conclusions: Antiparkinsonians availability of drugs in hospital pharmacies is low. In the network of retail pharmacies there antiparkinsonians availability of drugs, but however the most commonly used drugs (biperideno and levodopa) have poor coverage. The drug most commonly used to treat Parkinson's is dopamine, in commercial form because of its low cost and effectiveness. There is difficulty in acquiring medicines antiparkinsonians the afore mentioned issues, which results in inadequate control of the disease and low levels of perceived of quality of life

Keywords: Quality of life, Chronic disorder; Parkinson; Motor system.

\section{Introduction}

Parkinson's disease (PD) is a type of movement disorder secondary to dopamine deficiency. It is described that the fundamental lesion falls on the compact part of the substantia nigra (SN), which is part of the basal ganglia. PE produces a progressive disappearance of the dopaminergic neurons of the nigrostriatal system, with depigmentation and consequent gliosis [1].

A prevalence of 160 cases is reported for every 100,000 people in Western Europe. With an increase of $4 \%$ in the population over 80 years of age; although a peak incidence of the disease is reported above 50 years of age and reported as infrequent in people less than 40 years of age. An estimated one billion patients with PD worldwide are estimated [1,2].

In Ecuador, around 1000 cases are reported among patients treated in the care units belonging to the Ecuadorian Institute of Social Security (IESS), and the Eugenio Espejo Hospital. In the city of Riobamba, no records were found on the incidence and prevalence of Parkinson's disease, but there is a registry of patients with the disease that exceeds 75 patients [2].

The most significant clinical manifestation is the loss of muscle control in a progressive and insidious way, which may be associated with joint pains, limited movement speed, graphic alterations, irregularity of the tracing and as culminating movement alterations. of rhythmic oscillatory type in the manner of coins [3].

The diagnosis of Parkinson's disease is based on individual and family medical history. The observation plays a fundamental role since it is a fundamental element to detect the tremor and the alterations of the movement that facilitate the diagnosis of the disease $[3,4]$.

It is reported that PE, like other chronic diseases, negatively influences the perception of health-related quality of life (HRQoL) of sick patients. Hence, it is vital to maintain a strict control of the disease, which is achieved with adequate and systematic treatment with drugs that provide dopamine such as l-dopa. The l-dopa supplies the dopaminergic deficit, partially or totally reducing the clinical manifestations of the disease [5-9].

When considering PD as a chronic disease, antiparkisonian drugs act as a therapeutic measure aimed at alleviating the neurological symptoms and improving the quality of life of patients with $\mathrm{PD}$, being essential the administration of these drugs in a systematic and chronic manner [10].

It follows from the foregoing that it is indispensable to maintain a permanent supply of these drugs to the pharmacy network to ensure that they can be acquired by patients suffering from $\mathrm{PE}$, since without them they are necessary to achieve 
an adequate control of the disease and, in this way, raise the perception of HRQoL of patients with this disease [11].

This is why, considering that PE causes symptoms and signs that limit the perception of HRQoL and that the adequate supply of drugs for the treatment of the disease is vital; it was decided to carry out this work with the aim of determining the availability of antiparkisonian drugs in the pharmacies of the Riobamba municipality.

\section{Material and Methods}

A descriptive study was carried out with the objective of determining the availability of antiparkisonian drugs in the pharmacies of the Riobamba municipality in the period between June and August of 2017.

The universe was constituted by the pharmacies belonging to the basic hospitals of the municipality (Provincial General Teaching Hospital of Riobamba and the Ecuadorian Institute of Social Security), as well as the rest of pharmacies and medical dispensaries of the city of Riobamba. The sample was determined by simple random sample and was constituted by 22 premises that issue medicines including hospital pharmacies.

In order to carry out this work, a work team constituted by the authors of the research was integrated, which included the total of units determined in the sample. In all these institutions, a survey was carried out, both for patients and for pharmacy workers, which allowed us to obtain data on the different variables incorporated in the research.
In parallel, the research team interviewed 78 patients with PD and 6 health professionals, specialists in the area of neurology, who maintained direct interaction with them.

For the analysis and interpretation of the results, an Excel database was created with the information collected which was processed in an automated way using the statistical package SPSS-PC in its version 20.5 for Windows. The information was summarized by absolute frequencies and percentages for the qualitative variables and measures of central tendency and dispersion were used for the continuous quantitative variables. The $95 \%$ confidence intervals were estimated to complete the point estimate of the measures mentioned.

\section{Results}

When making visits to pharmacies and medical clinics in the city it was possible to verify as a result that $81.82 \%$ of them had antiparkisonian drugs in their stock (Table 1).

When applying the survey in the two hospitals visited, it was evidenced that only one of them had availability of antiparkisonian drugs for free delivery to patients. The drug with the greatest presence was biperiden and it was found that there is no stable supply that allows it to remain in sufficient quantities throughout the year.

Those with the greatest presence were akinetón, sinemet and cabergoline, which were found in $77.27 \%, 63.64 \%$ and $59.09 \%$ respectively of the total pharmacies visited. Other drugs such as biperiden and levodopa were only found in the stock of $4.55 \%$ of the places visited (Table 2).

Table 1: Distribución de farmacias según presencia de medicamentos antiparkinsonians.

\begin{tabular}{|c|c|c|c|c|c|c|}
\hline \multirow[b]{2}{*}{ Antiparkinsonians drugs } & \multicolumn{2}{|c|}{ Total } & \multicolumn{2}{|c|}{ Hospital pharmacies } & \multicolumn{2}{|c|}{ Retail pharmacies } \\
\hline & No. & $\%$ & No. & $\%$ & No. & $\%$ \\
\hline $\begin{array}{c}\text { No Presence of antiparkinson } \\
\text { drugs }\end{array}$ & 4 & 18,18 & 3 & 15,00 & 1 & 50 \\
\hline
\end{tabular}

Source: Survey

Table 2: Distribution of pharmacies according to the presence of antiparkisonian drugs.

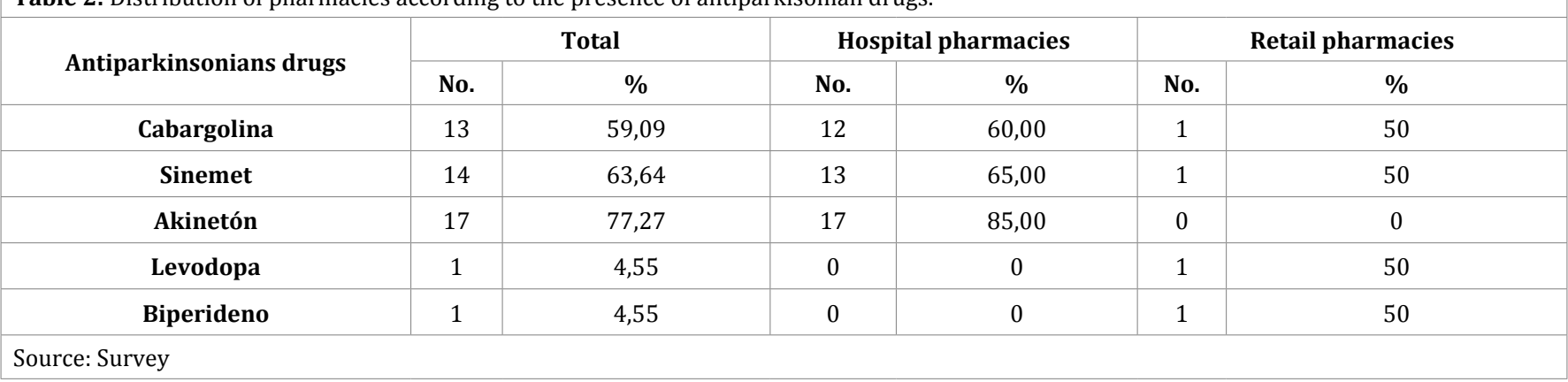

Levodopa and biperiden, were only present in one of the two hospital pharmacies; which also had in stock with cabargolina and sinemet. The akineton was only found in retail pharmacies.

Another result to note that in $77.27 \%$ of the cases these drugs were dispensed under a medical prescription, in addition to which they have a stable supply throughout the year (Table 3).

The patients interviewed said that only in $37.5 \%$ of the cases can they get the indicated treatment in the hospital pharmacies, 
Table 3: Distribution of antiparkisonian drugs according to prescription with medical prescription.

\begin{tabular}{|c|c|c|}
\hline \multirow{2}{*}{ Medical prescription } & \multicolumn{2}{|c|}{ Total } \\
\cline { 2 - 3 } & No. & $\%$ \\
\hline With Medical prescription & 17 & 77,27 \\
\hline $\begin{array}{c}\text { Without Medical } \\
\text { prescription }\end{array}$ & 5 & 22,73 \\
\hline
\end{tabular}

Source: Survey

so they have to go, relatively frequently, to the private network of dispensaries, although they said that they have a economic and affordable cost to the monetary possibilities of the majority of the population.

The $23.71 \%$ of patients reported that drugs purchased in hospitals were left over for the monthly treatment, while $76.69 \%$ stressed that they were insufficient for what they were forced to acquire in the private network, as alternative to guarantee your medication.

The $66.66 \%$ of the health professionals interviewed consider that the supply and free delivery of these medicines to patients with PD is insufficient. In addition, they pointed to biperiden as the most prescribed, followed by levodopa.

\section{Discussion}

Continuous administration, and in adequate doses, is one of the important factors in maintaining control of PD; In spite of describing adverse reactions by the use of these compounds, it is important to reduce tremor of movement, bradydemicity and muscular rigidity, in order to maintain or elevate the perception of HRQoL of these patients. 8, 10 If the patient can't acquire his treatment, completely and systematically, the course and evolution of the disease will be towards prostration [13].

In the network of dispensaries and private pharmacies of the municipality, the availability of drugs for the treatment of PD can be considered as satisfactory, not behaving in the same way in the hospitals visited. This element can bring disadvantages and difficulties that act negatively on the control of the disease; hindering access to necessary medications for patients with PD for different reasons among which those related to the economic issue, proximity and accessibility, among others, can be identified as more prevalent.

It should be noted that Ecuadorian health policies indicate that basic hospitals are responsible for ensuring the necessary medication to achieve control of chronic diseases, within which PE is. When there is a lack of supply, it is difficult to acquire drugs for the control of PD and patients have to resort to other alternatives in order to have the treatment indicated for their condition. This situation means that on multiple occasions they have to acquire other medications that are not ideal since the presence of biperiden and levodopa in the extra hospital network is quite low.

This situation may lead to patients not adhering to the treatment; which, despite having an economic cost, is not available in sufficient quantities to meet the demands of patients with PD. Failure to achieve an adequate supply of these drugs makes it impossible to control the disease, with the consequent increase in symptoms and decreased perception of HRQoL of them.

Patients highlight that the main problem is the availability of antiparkisonian drugs in hospitals and in the retail network, and they also stated that the medical prescription is correctly collected, which, in addition to serving for legal and legal control of the dispensarization of medicines is also used to evaluate the demand for them in the Riobamba municipality. Once the real need of antiparkisonian drugs has been determined, it should be included in the allocation planning of the Ministry of Public Health with the corresponding increase due to the presentation of new cases.

Regarding the activities of the professionals, they recommend medications in their specialty consultation. In some cases, professionals refuse to issue a prescription with a prescription, because they avoid being legally punished at some point by issuing a document that is not allowed by law.

Biperiden is the compound with the highest number of prescriptions, followed by levodopa (20.0\%). It is reported that $66.6 \%$ of patients with PD are able to control the disease with the administration of only one of them, these being the most effective drugs to control the dopaminergic deficit that causes the varied symptomatic courtship of the disease [14-17].

Maintaining an adequate supply of antiparkisonian drugs in both the public and private networks is the ideal measure for patients with PD to acquire it free of charge and to control the activity of the disease. It is recommended to conduct a survey to know the real needs of antiparkisonian drugs in order to maintain a stable supply.

\section{Conclusion}

There is an adequate availability of antiparkisonian drugs in the private pharmacy network of the city of Riobamba, although the existence of the drugs with the highest demand, biperiden and levodopa, is really low.

In the hospital system there is difficulty in obtaining drugs aimed at achieving control of the symptoms and signs of PD. It is determined by the limited availability of the most commonly used medications.

\section{Conflicts of Interest}

The authors declare that there are no conflicts of interest.

\section{References}

1. Arroyo Álvarez de Toledo L, Fuentes Maestro V. Enfermedad de Parkinson. Pharm Care Esp. 2012; 14(3):128-131.

2. Serrano-Dueñas M. Enfermedad de Parkinson, hemicuerpo afectado y depresión. Rev neurol 2000; 31 (12): 1109-1112.

3. Divisón Garrote JA, Escobar Cervantes C, Seguí Díaz M. Prediagnóstico de las presentaciones de la enfermedad de Parkinson en la atención 
primaria un estudio de control de caso. Revista española de medicina de familia. 2015;21(5): 284-286.

4. Friedman JH. Parkinson's disease psychosis 2010: a review article. Parkinsonism Relat Disord. 2010; 16(9):553-560. DOI:10.1016/j. parkreldis.2010.05.004

5. Pla Casamitjana CF, García S, Zárate Méndez A, Hernández Salazar M, Sauri Suárez S, Meza Dávalos E, et al. Calidad de vida en pacientes con enfermedad de Parkinson y estimulación cerebral profunda. Med Int Mex. 2007; 23:7-14.

6. Martínez-Jurado E, Cervantes-Arriaga A, Rodríguez-Violante M. Calidad de vida en pacientes con enfermedad de Parkinson. Rev Mex Neuroci. 2010; 11(6):480-486.

7. Peto V, Jenkinson C, Fitzpatrick R. PDQ-39: a review of the development, validation and application of a Parkinson's disease quality of life questionnaire and its associated measures. J Neurol 1998; 245 (Suppl 1): 10-4.

8. Solis-Cartas U, Prada-Hernández D, Crespo-Somoza I, Gómez-Morejón J, de-Armas-Hernandez A, Garcia-González V, et al. Percepción de calidad de vida relacionada con la salud en pacientes con osteoartritis de manos. Revista Cubana de Reumatología. 2015; 17(2).

9. Solis Cartas U, Barbón Pérez 0, Martinez Larrarte J. Determinación de la percepción de calidad de vida relacionada con la salud en pacientes con osteoartritis de columna vertebral. Rev Archivo Médico de Camagüey. 2016; 20(3):1-8.

10. Abaroa L, Verhagen Metmanb L, Arakaki T, Arce M, Garretto N. Zolpidem en la enfermedad de Parkinson. Neurología Argentina. 2014; 6(4):230-233.
11. Mínguez-Mínguez S, García-Muñozguren S, Solís-García del Pozo J, Jordán J. Calidad de vida y adherencia al tratamiento en pacientes con enfermedad de Parkinson. Rev Duazary. 2015; 12(2):37-45. DOI: 10.21676/2389783X.1470

12. Martínez-Lapiscina E, Pulido-Fontes L, Erro-Aguirre ME. Manejo terapéutico de las fluctuaciones motoras en la enfermedad de Parkinson. Rev Neurol.2012; 54(Suppl 5):S25-S32.

13. Lee VW, Pang KK, Hui KC, Kwok JC, Leung SL, Yu DS, et al. Medication adherence: Is it a hidden drug-related problem in hidden elderly? Geriatr Gerontol Int. 2013; 13(4):978-985. DOI:10.1111/ggi.12042

14. Santos García D, de Deus T, López Pazos E, Macías Arribi M, Llaneza González MA, Echarri Piudo A, et al. Manejo de las complicaciones relacionadas con la infusión intraduodenal de levodopa/carbidopa en pacientes con enfermedad de Parkinson. Rev Neurol. 2014; 58(11):505-515.

15. Markotic F, Cerni Obrdalj E, Zalihic A, Pehar R, Hadziosmanovic Z, Pivic G, et al. Adherence to pharmacological treatment of chronic nonmalignant pain in individuals aged 65 and older. Pain Med. 2013; 14(2): 247-256. DOI:10.1111/pme.12035

16. Luquin MR, García-Ruiz PJ, Martí MJ, Rojo A, Vela L, Grandas F, et al. Levodopa en el tratamiento de la enfermedad de Parkinson: mitos y realidades. Rev Neurol. 2012; 55(11): 669-88.

17. Stocchi F, Rascol O, Kieburtz K, Poewe W, Jankovic J, Tolosa E, et al. Initiating levodopa/carbidopa therapy with and without entacapone in early Parkinson disease: the STRIDE-PD study. Ann Neurol. 2010; 68(1):18-27. DOI:10.1002/ana.22060 